\title{
Extending working life: experiences from Sweden, 1981-2011
}

\author{
Haodong $Q^{1,2, *}$, Kirk Scott ${ }^{3}$ and Tommy Bengtsson ${ }^{3,4}$
}

\section{Abstract}

Population ageing is making it increasingly difficult for countries to sustain their current levels social welfare transfers from the economically active population to the dependent elderly. To meet this challenge, the Swedish government has implemented various reforms since the 1990s aimed at reducing incentives to take early retirement. However, a critical question has emerged in response to these reforms: namely, whether members of certain socially and demographically disadvantaged groups will, in practice, be able to work longer. This paper provides a detailed overview of retirement trends in Sweden, disaggregated by educational attainment, health status, and country of birth. Our results show that the growth pattern in the average effective retirement age since the mid-1990s was shared by individuals regardless of their educational level, health status, or country of birth. This shared growth pattern suggests that it is possible to extend the working lives of all groups of individuals, regardless of their socio-economic and demographic characteristics.

\section{Introduction}

The age at which an average worker retires has been rising in many developed countries over the past two decades (OECD 2017). Sweden is no exception. Since the mid-1990s, and after a period of decline lasting several decades, the average effective retirement age in Sweden has increased from 62.9 to 64.6 for women and from 63.6 to 65.2 for men (Bengtsson and Qi 2018). While these trends are

\footnotetext{
${ }^{1}$ Malmö University, 20506 Malmö, Sweden

${ }^{2}$ Stockholm University Demography Unit, Sweden

${ }^{3}$ Centre for Economic Demography, School of Economics and Management, Lund University, Sweden

${ }^{4}$ IZA Fellow

${ }^{*}$ Correspondence to: Haodong Qi, haodong.qi@ sociology.su.se
} 
promising, they are not large enough to counteract the increasing share of lifetime spent in retirement (Bengtsson and Scott 2011). Thus, sustaining current levels social welfare transfers from the economically active population to the dependent elderly is becoming more difficult. To meet this challenge, working life needs to be further prolonged.

In 2019, the Swedish parliament approved a plan to gradually increase the minimum age for receiving old-age pension benefits from 61 years currently to 64 years, and to increase the minimum age for receiving guaranteed pension benefits (a portion of the national retirement pension entitlement that is paid to those who have had little or no pension-qualifying income) from 65 years currently to 67 years in 2026. At the same time, the age at which individuals have the right to continue to work was also raised. The aim of these new policies is to increase the average effective retirement age. However, a critical question has emerged in response to these reforms: namely, whether these adjustments will have adverse welfare consequences for older individuals who struggle to continue to work. To address this question, it is useful to examine whether the pattern of growth in the effective retirement age since the mid-1990s was similar for individuals with different characteristics. Surprisingly, there has been little research analysing these retirement trends by socio-economic and demographic groups. In this paper, we provide a detailed overview of recent retirement trends in Sweden, disaggregated by educational attainment, health, and country of birth. We also discuss how institutional changes in the country's pension systems and retirement policies, as well as in its levels of human capital investment, might have differential effects on older workers with different socio-economic and demographic backgrounds.

\section{Background}

\subsection{Population ageing in Sweden}

The world population is expected to age rapidly during the 21 st century. Current projections indicate that by 2050, the share of the population over age 60 will reach $20 \%$ worldwide, and will be as high as one-third in Europe (UN 2015). For Sweden, this figure is expected to be around $30 \%$, or somewhat lower than the European average (SCB 2018).

This ageing process is not, however, new. Sweden was the second country in the world to join the group of countries considered "aged" by the United Nations. To join this club, the percentage of a country's population aged 65 or older must be $7 \%$ or higher. In Sweden, this milestone was passed in 1888, and the share of the elderly in the population has increased almost monotonically since then. Figure 1 shows the share of the population aged 65 or older from 1860 to 2018. An aspect of this process that is new in this century is that the ageing population is becoming more diverse than ever before. Today, $15 \%$ of all men and 17\% of all women aged 60-69 are foreign-born (SCB 2017), and these shares are expected to grow in the future. 
Figure 1:

The share of the Swedish population aged 65 years or older, 1860-2018

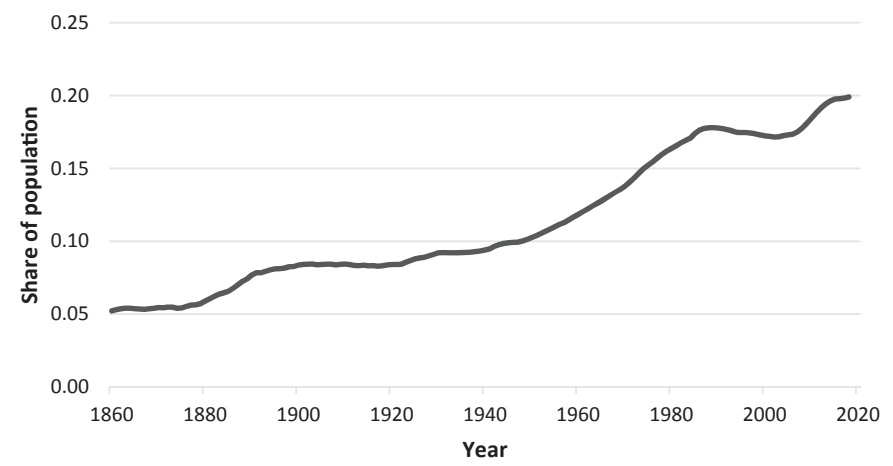

Source: Population by age and sex, 1860-2018, Statistics Sweden.

Moreover, we have entered into a new stage of population ageing in terms of its causes, which have, in turn, altered the consequences of ageing. In the first stage, which lasted until the second part of the 20th century in developed countries, the sole cause of population ageing was the decline in fertility, with Sweden being commonly used as an example of this trend (Coale 1957; Bengtsson and Scott 2010; Lee and Zhou 2017). During this stage, increases in life expectancy were primarily driven by declines in infant and child mortality. This process moved in the opposite direction of the decreasing trend in fertility. Thus, the population became younger as more years of life were added before than after retirement (Coale 1957; Lee 1994). In the second stage of population ageing, which we are currently experiencing, the process is driven by declining old-age mortality. As a result, more years of life are being added after retirement than at working ages (Lee 1994), and the share of the elderly in the population is growing, while the share of the population who are of working ages is declining. Could immigration or an upswing in fertility reverse this change in the dependency ratio? The short answer is that they most likely cannot. The effect of migration on population ageing is generally regarded as minor (Murphy 2017); and, since population ageing is a global phenomenon, the movement of people from one country to another will not alter the overall ageing process. Similarly, a rapid increase in fertility is improbable. Moreover, even if fertility started increasing today, it would take some 25 years for the labour force to grow, and the dependency ratio would increase in the meantime. For these reasons, scholars and policy-makers are focusing their attention on how our social systems can be adapted to meet the challenges associated with an increasing trend in the number of elderly people per worker - especially as increases in the pensioner-to-worker ratio are being accompanied by rising per capita costs for institutional care, home care, and general health care for the elderly. 


\subsection{The current Swedish pension system}

The current Swedish old-age pension system, which provides benefits that are based primarily on an individual's actual contributions during his/her working life, was approved by the Swedish parliament in 1994, and was first implemented in 1999. Unlike the previous defined benefit system, the current system is financially stable, and provides strong incentives for postponing retirement. These incentives were created through a new way of calculating benefits that is based on a worker's contributions over his/her entire working life. To calculate pension entitlements, an individual's accumulated contributions, plus interest-based returns, are essentially divided by his/her remaining life expectancy at the age of retirement. The purpose of this approach is to encourage workers to work longer, as additional years of work may be expected to both increase the total amount of pension wealth and reduce the estimated remaining life expectancy. These adjustments should, in turn, result in higher monthly benefit payments for retirees.

The pension system has three pillars: old-age pensions administrated by the Swedish Pension Agency, occupational pensions administered through private funds, and individually invested pension accounts. The benefits provided by this system are supplemented with state-guaranteed pension benefits, as well as with housing and old-age allowances. These supplemental schemes are paid for directly from the state budget, and correspond to $11 \%$ of public pension benefits (Pensionsmyndigheten 2018). The disability pension system, which was previously part of the state pension system, became part of the social insurance program in 2003.

While the Swedish old-age pension system is very flexible, with provisions for early and partial retirement (albeit with financial penalties in the form of lower pension income), the majority of workers retire at age 65 , when they become eligible to receive guaranteed pension benefits, housing allowances, and old-age support. Moreover, individuals rarely return to market work after they begin receiving pension benefits. In 2017, just $0.3 \%$ of recipients of old-age pension benefits were engaged in labour market activities (Pensionsmyndigheten 2018).

Occupational pensions in Sweden are generally based on agreements between trade unions and employers, with a very small number of exceptions that are negotiated on an individual basis. These schemes play an important role in supplementing old-age pension entitlements, which are usually low due to an upper ceiling on benefits. As having a private pension outside of the broad occupational pension schemes is rare in Sweden, most retirees rely solely on public pension programs, occupational pensions, and/or guaranteed pensions. In 2017, old-age and occupational pension benefits accounted for around $65 \%$ of the annual income of an average retiree. Currently, postponing retirement by one year will increase an individual's annual pension income by about $5 \%$, since the remaining life expectancy at age 65 is roughly 20 years. An additional incentive for postponing retirement until reaching age 65 is that the tax rate for workers is reduced after age 65 .

Supplemental old-age allowances, in addition to pensions and housing allowances, are paid out to approximately $10 \%$ of the Swedish-born population aged 69+. 
Immigrants from non-EU countries have the lowest pension benefits; a pattern that has been observed all over Western Europe (Heisig et al. 2017). For this reason, migrants tend to be more reliant on these allowances than the native-born population. Pension entitlements are based on an individual's contributions over his/her working life. In many cases, a migrant will have a combination of a relatively short work history and relatively low wages, both of which decrease his/her eligibility to receive a full pension (Sjogren Lindquist 2017). Indeed, almost all old-age support allowances are paid out to immigrants (Gustafsson et al. 2018). However, while immigrants tend to have lower old-age and occupational pension benefits than natives, there are differences between immigrant groups.

The early retirement/disability pension scheme has undergone various reforms in recent years. Initially, this benefit program was intended purely as a support for disabled individuals. But starting in the 1970s, it was used as an early retirement program for older workers who became unemployed and found re-entering the labour market very difficult. In the first decade of this century, the disability pension system was reformed to lower the number of individuals who were eligible to take advantage of it. In 2003, the unemployment condition was removed, and the requirements for receiving disability pension benefits became increasingly stringent. Currently, a disability pension is only available to individuals who have limited working capacity for medical reasons.

\subsection{The effective retirement ages}

Although the age at which an average worker in Sweden effectively retires has increased for both men and women, since the mid-1990s, the observed rate of increase has not been sufficient to counteract the increasing number of years people live after retirement (Bengtsson and Scott 2011). This trend is making it increasingly challenging for Sweden to sustain current levels of social welfare transfers from the economically active population to the dependent elderly. To meet this challenge, the average working life needs to be further prolonged. In 2019, the Swedish parliament approved a plan to gradually increase the minimum age for receiving old-age pension benefits from 61 years currently to 64 years, and to increase the minimum age for receiving guaranteed pension benefits from 65 years currently to 67 years in 2026. At the same time, the age at which individuals have the right to continue to work was also raised. The aim of these new reforms was to further increase the effective retirement age. However, a critical question was posed in response to these reforms: namely, whether workers who are engaged in physically demanding occupations will be able to work longer. To address this question, we have to look at whether the increasing trend in the effective retirement age over the past two decades has been shared by individuals with different levels of health and human capital. An area of research that has received little attention from scholars is the retirement behaviour of ageing immigrants. Immigrants in Sweden tend to receive lower pension benefits than natives, usually due to a combination of having shorter 
working histories, lower wages, and/or being ineligible to receive guaranteed pension benefits if they have resided in Sweden for less than 40 years (Sjogren Lindquist 2017). These disadvantages were exacerbated by the 1994 old-age pension reform, as the current old-age pension system calculates a worker's pension benefits based on his/her earning history throughout his/her entire working life (whereas the previous system defined benefits based on the best 15 years of a worker's earning history). While natives usually spend their entire economic life-cycle in Sweden, migrants do not. Thus, on average, the pension benefits migrants receive in the current pension system are lower than those of natives, largely because they spent fewer years contributing to the system, and had lower average life-time earnings. Moreover, immigrants tend to rely on disability pension benefits more than natives. However, as the eligibility rules for the disability pension program have become increasingly stringent, immigrants' reliance on this early retirement pathway has been reduced. One strategy immigrants can use to respond to these institutional changes is to maximise the number of years they contribute to the system by postponing retirement - perhaps to an even greater extent than native-born Swedes. However, the question of whether immigrants are able to work longer has yet to be answered.

\section{Data}

The analyses in this paper mainly rely on data from the Swedish Interdisciplinary Panel (SIP), which consists of individual-level data from several different administrative registers, including the income and taxation register, the inpatient register, the educational register, and the total population register. These multiple registers have been merged to create a longitudinal database covering roughly 12 million unique individuals born between 1930 and 1980 who resided in Sweden sometime during the 1968-2011 period. The database allows researchers to examine from a life course perspective the labour supply behaviour of individuals towards the end of their careers.

In calculating the effective retirement age, we use data on each individual's labour income and pension income, obtained from the income and taxation register, to determine his/her participation in the labour force (more details below). Information from the inpatient register, the educational register, and the total population register are used to identify each individual's socio-economic and demographic characteristics. This information allows us to disaggregate the labour force participation rates, as well as the effective retirement age, by gender, education, health, and country of birth.

\section{Calculating the average effective retirement age}

The average effective retirement age is defined as the expected age of withdrawal from the labour force, which is computed based on the static method (Scherer 
2002). In our analysis, we calculate this indicator by different socio-economic and demographic groups based on gender, education, health status, and country of birth.

We start by computing the intensity of labour force participation for each individual $i$, in group $j$, at age $x$. An individual's labour force participation is measured by his/her annual labour income, as a share of total income (including labour income, and the sum of old-age and disability pension benefits), which can be written as:

$$
L(i, j, x)=\frac{Y(i, j, x)}{Y(i, j, x)+B(i, j, x)}
$$

where $Y$ is labour income, $B$ is the sum of old-age and disability pension benefits. The labour force participation rate for group $j$, at age $x$, can be calculated by,

$$
L(j, x)=\frac{\sum_{i}^{N_{j, x}} L(i, j, x)}{N_{j, x}}=\frac{\sum_{i}^{N_{j, x}} \frac{Y(i, j, x)}{Y(i, j, x)+B(i, j, x)}}{N_{j, x}}
$$

where, $N_{j, x}$ is the number of individuals in group $j$, at age $x$.

These group-specific labour force participation rates by age are then used to calculate the average effective retirement age for each group $j$. Hence, the groupspecific average effective retirement age, $A(j)$, is computed by

$$
A(j)=\sum_{x=55}^{70} \frac{L(j, x-1)-L(j, x)}{L(j, x=54)} \times x
$$

Note. We assume that all individuals are still working at age 54 ; hence, $L(j, x=$ $54)=1$. We also assume that no individuals are still working at age 70; hence, $L(j, x=70)=0$.

\section{Trends in the average effective retirement age}

\subsection{The overall trends}

Figure 2 shows the effective retirement age for men and women between 1981 and 2011. For women, the effective retirement age in 2011 was even higher than it was in 1981, as there was an obvious increase after the mid-1990s that erased the decreases in the preceding years. Men had roughly the same effective retirement age in 1981 and in 2011, but the decreases in the early period and the subsequent increases were more dramatic for men than they were for women. What is even more interesting to note here is that the gaps between the effective retirement age and the remaining life expectancy at age 65 were large and increasing. In 1981, men were expected to live 14 years after retirement, and women were expected to live close to 20 years. By 2011, this gap had expanded to 18 years for men and to 21 years 
Figure 2:

Effective retirement age and expected age at death for those surviving to age 65, 1981-2011, women and men
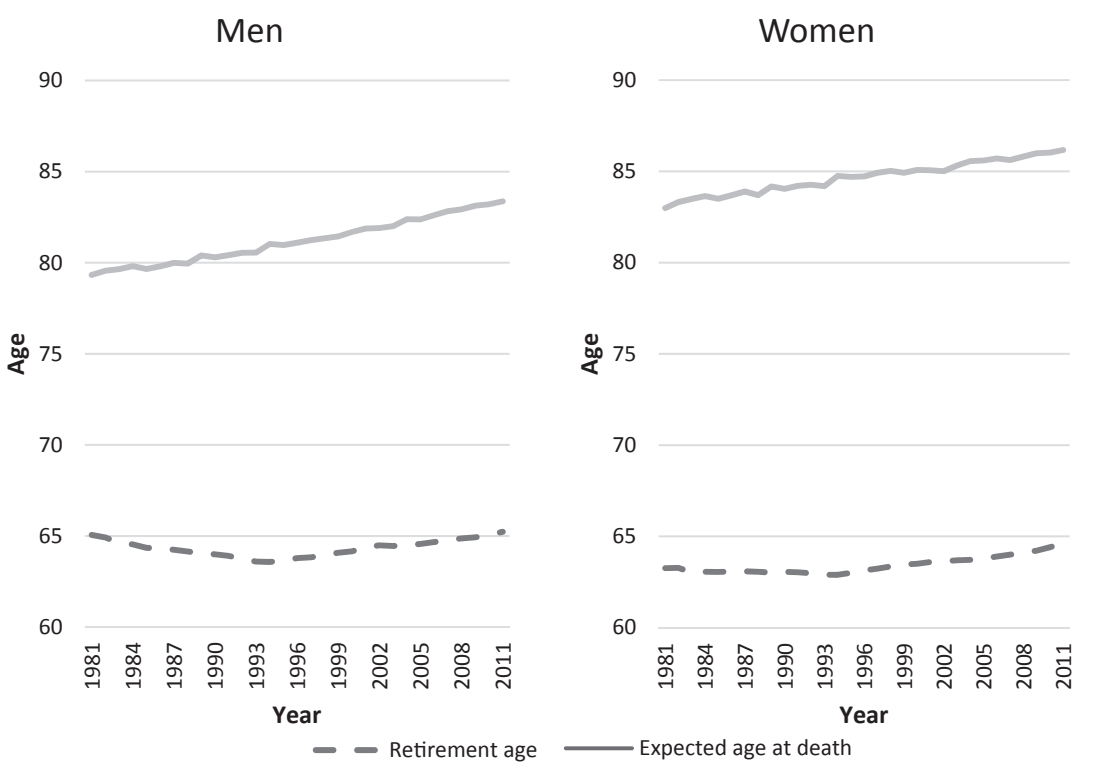

Source: Own calculations on the effective retirement ages using the Swedish Interdisciplinary Panel (SIP) from 1981 to 2011 . The expected age at death is the remaining life expectancies for those survived to age 65 , which are extracted from Statistics Sweden.

for women, even though the retirement age had increased by almost two years. This diagram underscores the options for - as well as the necessity of - increasing the legal retirement age. However, a critical question has been raised in response to these proposed changes: Will members of disadvantaged groups be able to adapt to policies that encourage people to work longer, and particularly those who have limited human capital, poor health, and/or are foreign-born?

\subsection{Trends by education}

Figure 3 shows the actual average retirement age from 1981 to 2011, broken down by educational level and sex. The most obvious point worth noting here is that there is a clear educational gradient in the age at retirement for both men and women. Thus, individuals with higher educational levels also had higher effective ages at retirement. Although women had a consistently lower retirement age at all educational levels, the pattern observed for women is largely the same as that for men.

Across educational levels, both men and women had fairly high effective retirement ages in 1981. Thereafter, these ages declined steadily until the beginning of the 
Figure 3:

Effective retirement age by education, 1981-2011, women and men

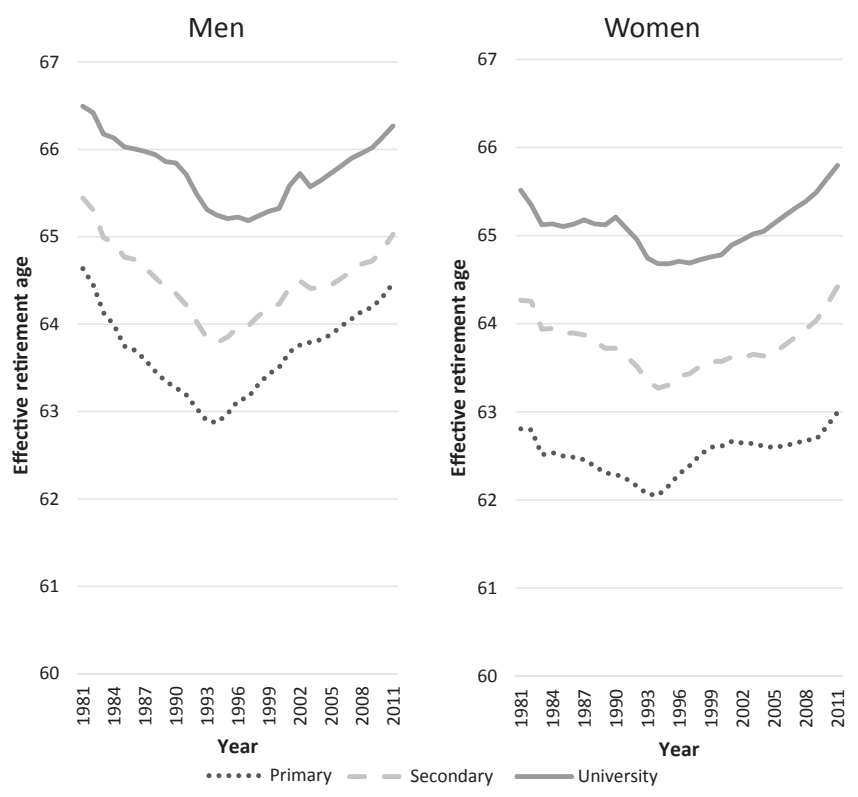

Source: Own calculations on the effective retirement ages using the Swedish Interdisciplinary Panel (SIP) from 1981 to 2011.

mid-1990s, when they started to gradually recover. During this period of recovery, the effective retirement ages of both men and women with primary and secondary education, and of men with higher education, returned to levels that were prevalent in the early 1980s. However, the effective retirement ages of women with higher education increased to a greater extent, reaching levels in 2011 that exceeded than those in the early 1980s.

The findings presented in this diagram give us reasons to be optimistic about the ability of individuals with physically demanding jobs to postpone retirement. As lower educated individuals do indeed retire earlier, the question of whether they are able to cope with working longer - and, thus, whether they are negatively affected by retirement policies that encourage workers to prolong their labour force participation - clearly arises. However, the increases in retirement age observed for these groups in the 1990s and the 2000s seem to suggest that having a low educational level is not a barrier to working longer.

\subsection{Trends by health status}

In addition to a lack of human capital (schooling), impaired health is another potential reason why some individuals may be unable to work longer. Impaired 
health can be an outcome of strenuous working conditions, but it can also be exogenous to working life. In either case, it is important to examine how different health patterns affect the age at retirement.

Figure 4 shows the changing effective age at retirement for men and women with different health statuses, measured as the number of hospital stays each person had while approaching age 60 . The line denoted no admissions indicates fully healthy individuals, defined as those individuals who did not have a hospital stay while between the ages of 55 and 59. The next two categories show progressively less healthy individuals, with the group having one stay, and the group having two or more stays. While it might be intuitively interesting to look at those individuals who had a higher number of stays, the small numbers of these cases make such an analysis impossible. For example, only $2 \%$ of the population aged 55-59 had two or more hospitalisations. If we added another category for individuals with three or more hospitalisations, we would have groups with such small numbers that any results would have to be discounted as random. Additional caveats worth mentioning here are that we only have information on illnesses and injuries that required hospitalisation, and that we only have data from the late 1980s onwards.

As expected, we observe a gradient in the retirement age that is negatively related to health. Those individuals with more hospital stays tended to retire at younger ages, with retirement occurring one to 1.5 years earlier for each level of decrease in health status. However, the steady increase in the retirement age starting in the early 1990s that was shown in Figure 3 is also apparent here. Unfortunately, a lack of health data for the entire period makes it impossible to examine the pattern during the 1980s, as we can with educational data. Our observation that those individuals with the worst health have considerably lower retirement ages than those individuals with the lowest education may confound our understanding of the ability of people with strenuous employment to continue working at higher ages. However, even here we see a steady increase over the past two decades.

\subsection{Trends by countries of birth}

Figure 5 shows the employment rates among older immigrants with different countries of birth in Sweden (vertical axis), and among the populations of the same ages population in the origin countries (horizontal axis). Immigrants' employment rates are calculated based on Swedish register data, and comparable figures from the origin countries are obtained from the OECD (2019), with employment rates by age group. These rates are the average over the 2005-2011 period. As Figure 4 shows, the levels of employment at older ages varied substantially depending on where the immigrants came from. Those who were from Greece had the lowest levels, while those who were from North America had the highest levels.

When we look at Figure 5, we can see that older immigrants' employment rates tended to be positively correlated with those of their non-migrant counterparts in their respective country of origin. If we assumed that the immigrants and their 
Figure 4:

Effective retirement age by health, 1989-2011, women and men
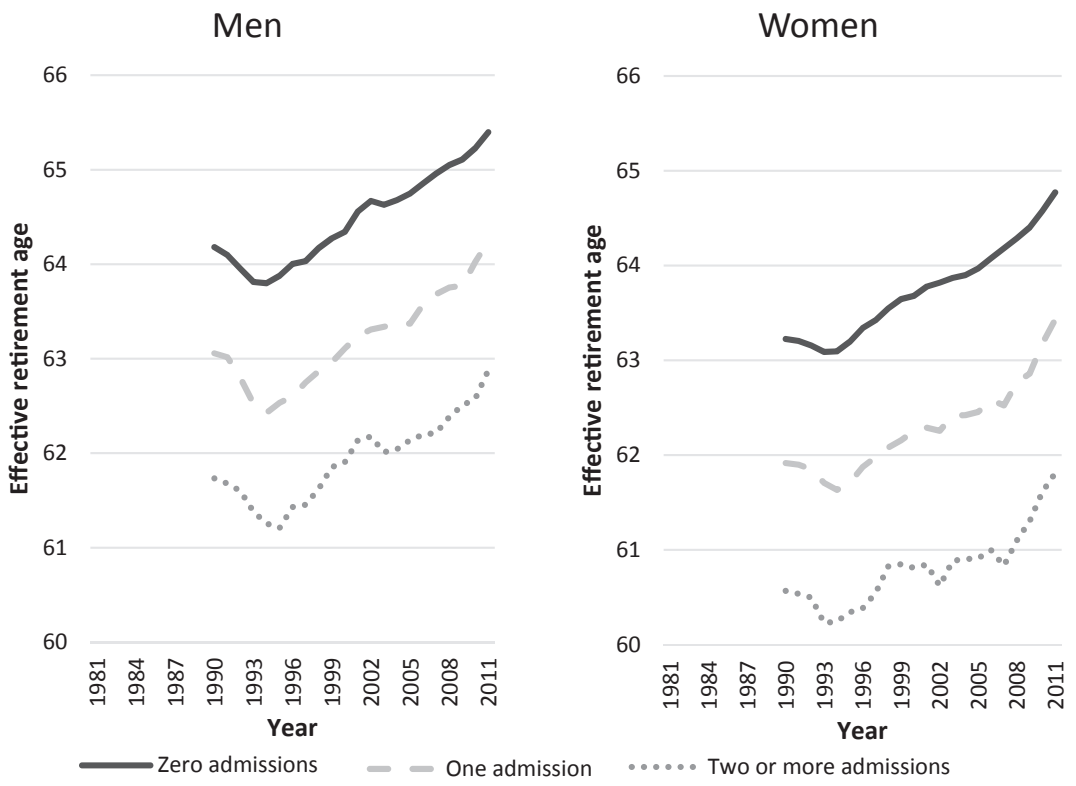

Note: Health is measured by the number of hospital admissions for each person while between the ages of 55 and 59, categorised by no admission, one admission, and two or more admissions.

Source: Own calculations on the effective retirement ages using the Swedish Interdisciplinary Panel (SIP) from 1981 to 2011.

counterparts who did not migrate were comparable in all their characteristics (such as age, gender, and education), this correlation would imply that immigrants' human capital endowment played a role in shaping their employment in later life. In other words, the low level of employment observed for some foreign-born groups might be attributable in part to some initial disadvantages that immigrants accumulated prior to leaving their country of origin. However, these disadvantages do not seem to prevent them from working longer. As Figure 6 shows, a recovery in the effective retirement age since the mid-1990s occurred not only among native-born Swedes and immigrants from high-income countries, but also among immigrants from Africa, Asia, the Balkan countries, the Middle East, and South America. Indeed, the growth trend for workers from low-income countries is even steeper.

\section{Mechanisms driving the growth in the effective retirement age}

While the growth in the old-age labour supply could help to mitigate the consequences of population ageing, the mechanisms that underlie this growth are poorly 
Figure 5:

Employment rates for immigrants in Sweden compared to employment rates for non-migrants in the source countries, 2005-2011

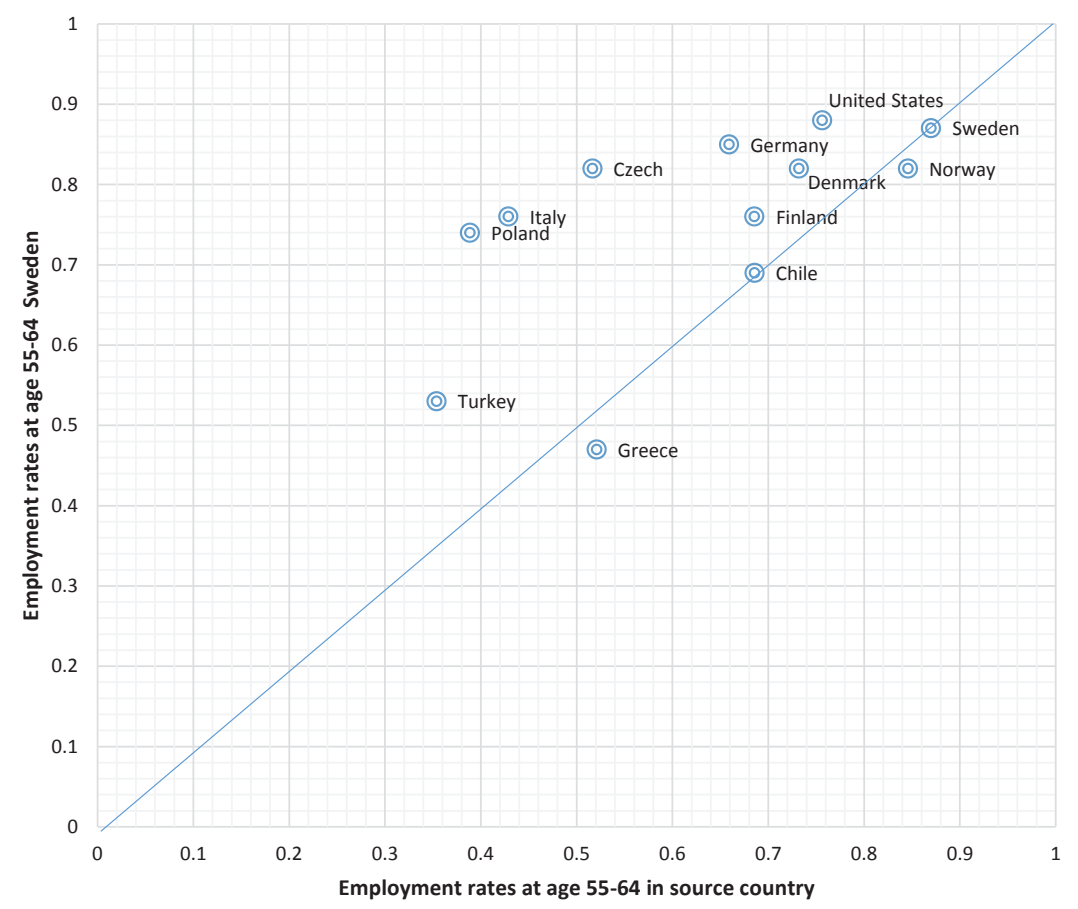

Source: Own calculations on immigrants' employment rates in Sweden using the Swedish Interdisciplinary Panel (SIP). Employment rates for the immigrants' home countries were obtained from the OECD (2019).

understood. Moreover, there is no generalisable research on how the mechanisms and the incentives for extending working life may vary across different socioeconomic and demographic groups. In this section, we discuss the potential explanations for the increase in the effective retirement age at the aggregate level, as well as at the group level.

\subsection{Explanations for the aggregate growth in the retirement age}

It has been argued that moving from a defined benefit to a defined contribution pension system and/or increasing the statutory retirement age might be effective measures for delaying entry into retirement. Many developed countries have indeed experienced these effects, with an increase in the elderly labour supply following the introduction of retirement legislation that discourages early retirement (Atalay and Barrett 2015; Staubli and Zweimuller 2013). 


\section{Figure 6:}

Effective retirement age by country of birth, men and women, 1981-2011
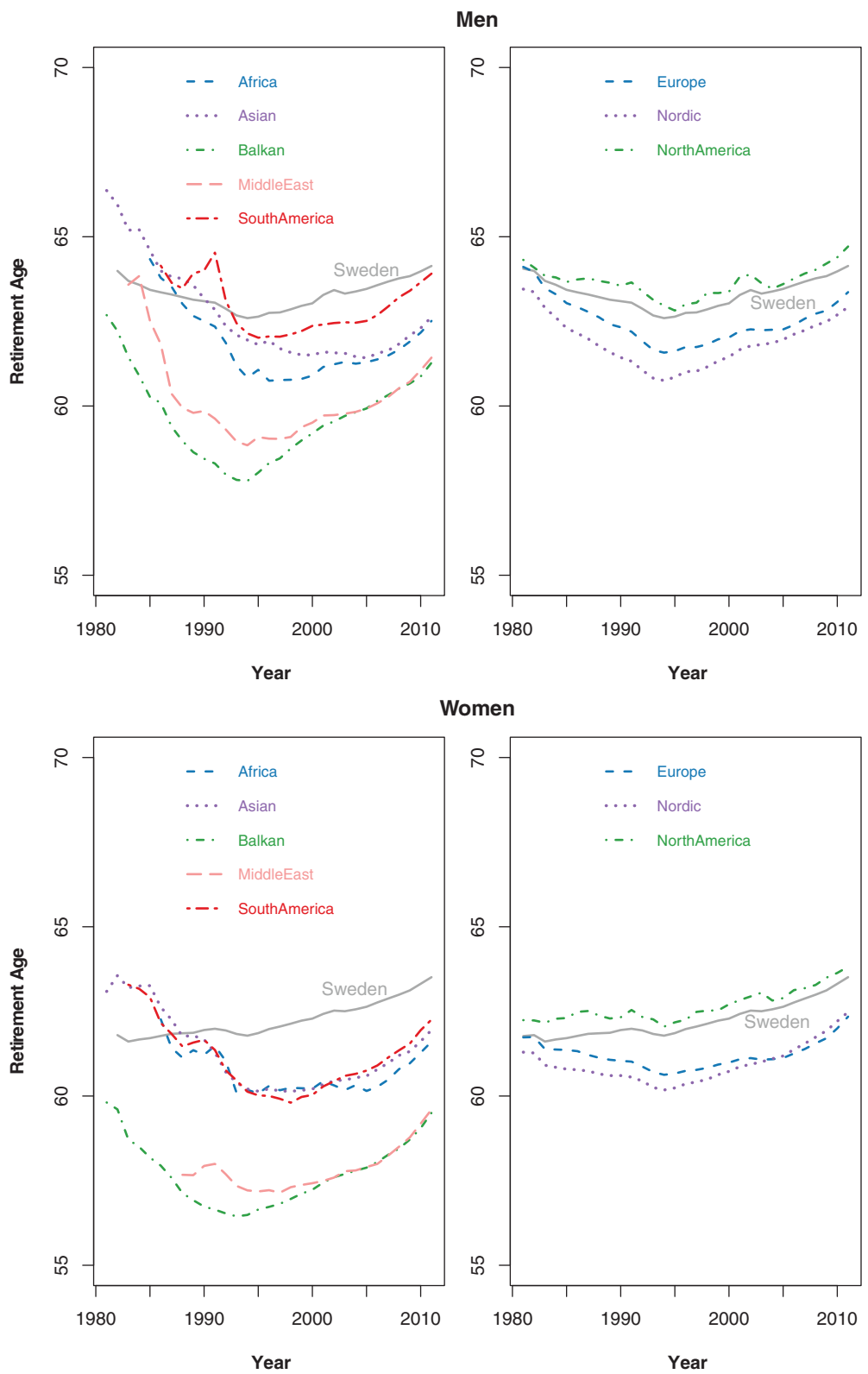

Source: Own calculations on the effective retirement ages using the Swedish Interdisciplinary Panel (SIP) from 1981 to 2011. 
Between 1970 and 1991, older workers in Sweden retired prior to reaching the statutory retirement age by claiming early retirement/disability pension benefits for non-health reasons, such as unemployment. This new use of the early retirement option was the prime reason for the decline in the effective retirement age (Hagen 2013). As we discussed above, the Swedish government eliminated the option of claiming disability pension benefits for labour market reasons, as well as the favourable rules for workers aged 60-64. This reform had a positive impact on the elderly labour force participation rate (Karlström et al. 2008).

The defined contribution system that came into effect in 1999 created even greater incentives to work longer, with benefits increasing in line with the number of years worked. Although some scholars predicted an overall increase of 2.5 years in the effective retirement age in response to the new system (Laun and Wallenius 2015), this impact has so far not been reported. The primary reason why the full effect of the new pension system has yet to be observed is that the shift from the old system to the new system has been gradual. Under the transition rules, the oldest cohort to be fully vested in the new system was born in 1954. Thus, the members of this cohort have not yet reached age 67 , which is the age at which the guaranteed right to continued employment ends.

Recent evidence for Sweden has, however, suggested that the labour supply effect of the new system might be smaller than expected. An examination of members of the 1944 cohort, whose pension benefits were reduced by $10 \%$ for men and 6\% for women because half of their pension benefits were converted to the new system, found that the increase in the effective retirement age was just 0.15 for men and 0.03 years for women (Qi et al. 2018). This finding implies that the 1994 Swedish pension reform played a minor role in driving the growth in the effective retirement age since the mid-1990s. Similar evidence has been reported for the US. It has, for example, been shown that the gradual increase in the full retirement age from 65 to 67 and the increase in pension credit after full retirement age that were announced in 1983 could account for only one-sixth of the increase in the labour force participation of men aged 65-67 between 1998 and 2004 (Maestas and Zissimopoulos 2010).

This evidence casts doubt on the explanatory power of pension reforms for the increase in the effective retirement age. Thus, the question of why older people have started working longer remains open. Some scholars have argued that the change in the pension rules provides only a secondary explanation for why older people have begun to work longer, and that the primary reason is the change in the human capital composition of the labour force (Maestas and Zissimopoulos 2010).

University education was expanding in many developed countries during the second half of the 20th century (Altbach et al. 2009). Many birth cohorts who were the early beneficiaries of these expansions have reached pensionable ages over the past two decades, resulting in a noticeable increase in the educational attainment of the retirement-age population. This growth in educational attainment has accounted for between one-third and one-half of the increase in older men's labour force participation in the UK, the US, and Canada since the mid-1990s (Schirle 2008; Blau and Goodstein 2010). 
Figure 7:

Educational composition, birth cohorts 1935-1947, Sweden

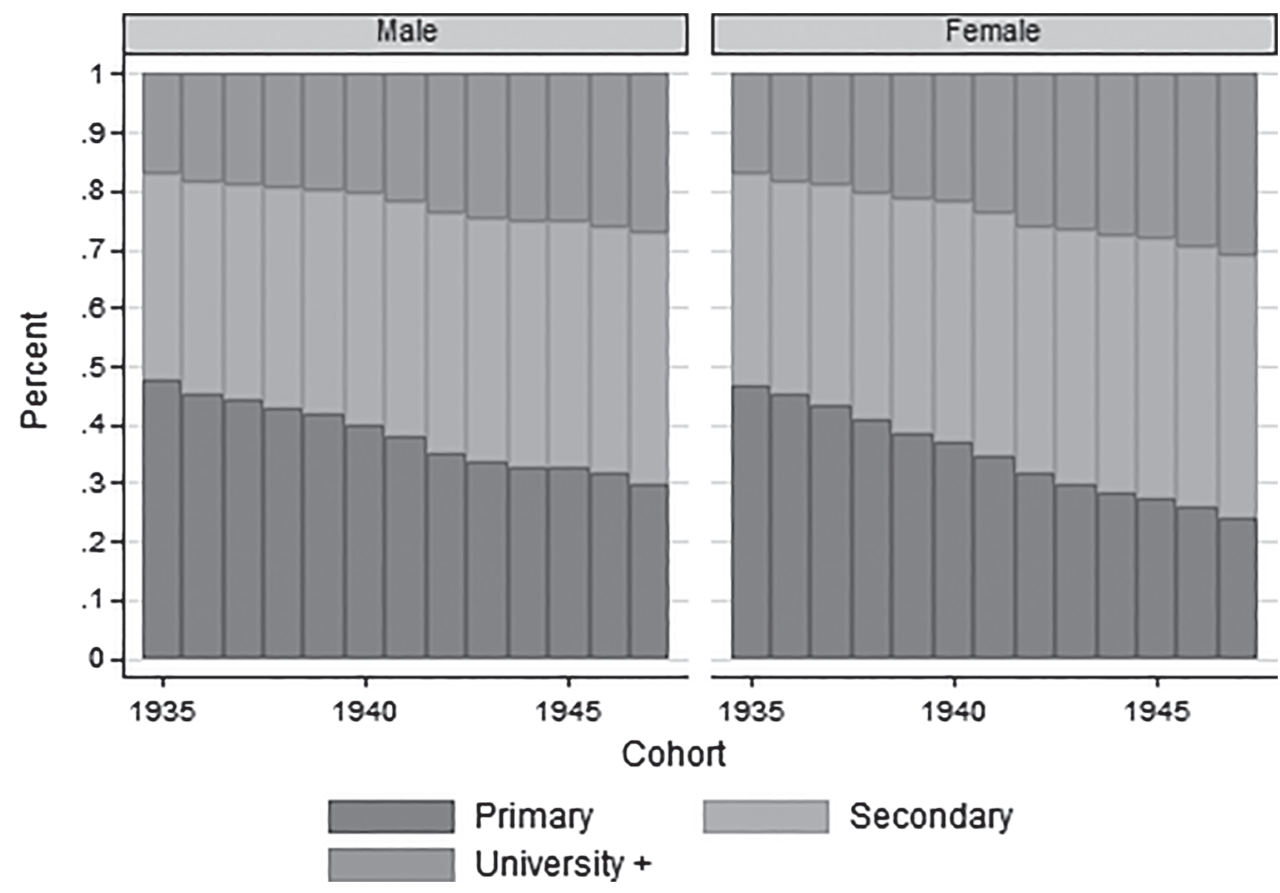

Source: Qi et al. (2016).

While the expansion in tertiary education was a worldwide phenomenon during the second half of the 20th century, Sweden was a country that exemplified this process. Enrolment and completion rates not only increased in Sweden; the number of higher education institutes in the country grew (Chudnovskaya and Kolk 2015). These developments resulted in higher educational attainment levels among those who reached retirement age from the mid-1990s onwards. Looking at Figure 7, we can see that for those born in 1935-1947 (the cohorts who reached age 60 in 1995-2007), the share of the population with university-level education increased, while the fraction with primary education declined (Qi 2016; Qi et al. 2016). This compositional change explained about a quarter of the growth in employment rates for women born in 1935-1947, but very little of the increase in labour force participation for their male counterparts.

In Sweden, there have been noticeable health improvements in the old-age population, with many diseases being diagnosed at higher ages than was the case in the past. For example, the average age of the first myocardial infarction increased by about three years between 1995 and 2010 (Modig et al. 2012; Modig et al. 2013), with a similar postponement being observed for hip fractures (Karampampa et al. 
Figure 8:

Health composition, birth cohorts 1935-1947, Sweden

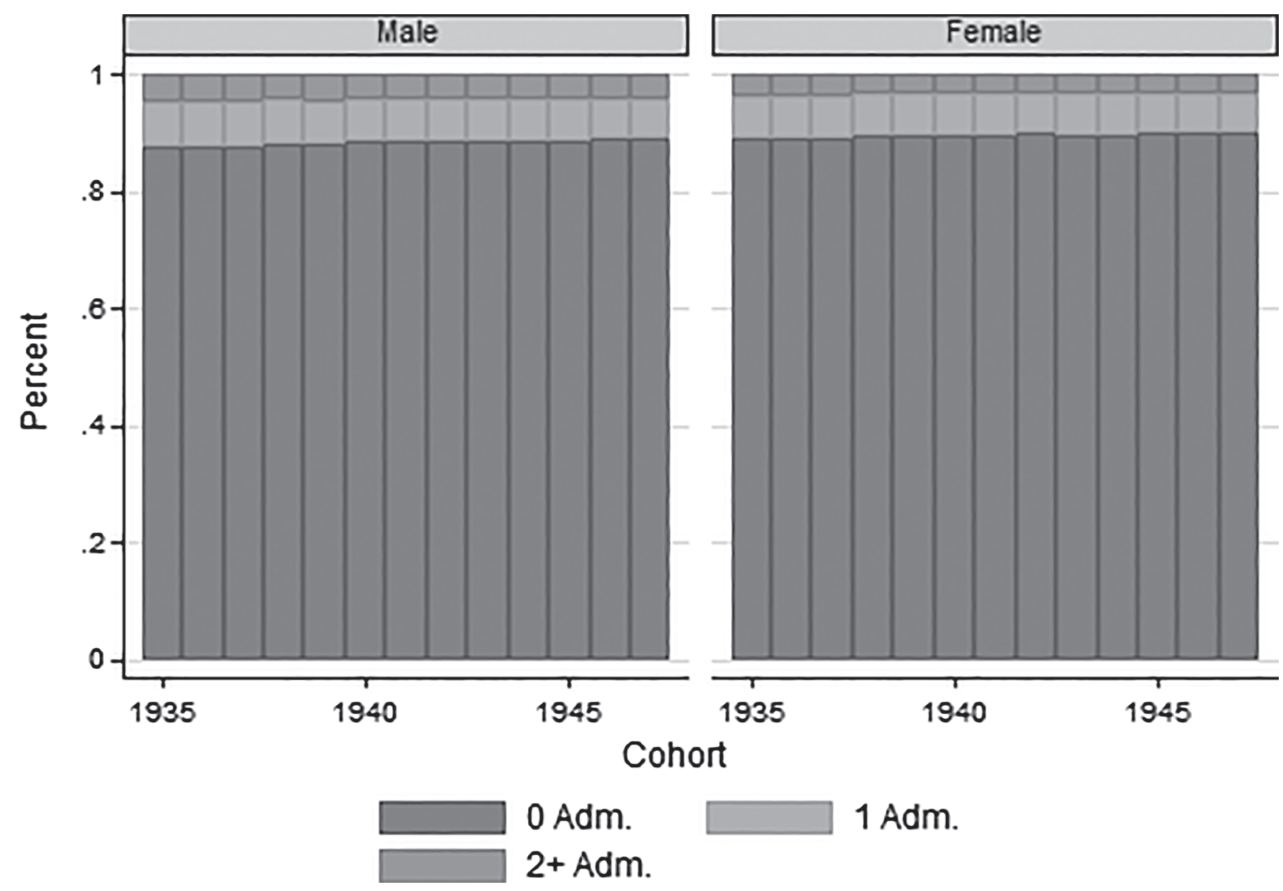

Note: Health is measured by the number of hospital admissions that each person had while between the ages of 55 and 59; categorised by no admission (0 Adm.), one admission (1 Adm.), and two or more admissions (2+ Adm.). Source: Qi et al. (2016).

2013; Karampampa et al. 2014). However, these health improvements are unlikely to be the main factors that explain the increase in old-age labour supply, as they are mostly concentrated among the oldest-old. The majority of people approaching retirement (aged 55-59) are in consistently good health. As Figure 8 shows, roughly $90 \%$ of those individuals born in 1935-1947 (the cohorts who reached age 60 in 1995-2007) have never been hospitalised. This high level of population health also gives us reason to believe that the extension of working life is not just desirable; it is quite possible.

\subsection{Explanations for the group-specific growth in the retirement age}

Our finding that there is a shared growth pattern in the average effective retirement age suggests that having a lack of human capital, impaired health, or an immigrant 
background are obstacles to extending working life. There is, however, little understanding about whether and, if so, how the mechanisms that underlie this pattern might differ across individuals with different socio-economic and demographic characteristics.

Some researchers have argued that changes in disability insurance and old-age pension benefits are significant factors in the increase in the old-age labour supply since the mid-1990s (Karlström et al. 2008; Johansson et al. 2015; Laun and Palme 2017). The critical question that arises is whether these reforms had the same impact on all older individuals.

The stricter rules for qualifying for disability insurance benefits might be having disproportionally adverse impacts on workers with low levels of human capital and impaired health, as they tend to rely on these benefits to a greater extent than other workers. Hence, the increases we observed in the effective retirement age for those individuals with primary education, and for the $10 \%$ of the population who were hospitalised between the ages of 55 and 59, might be more attributable to the disability insurance reforms than they are for individuals with higher levels of education and health.

For immigrants, and particularly for those from low-income countries, the mechanisms might be more complex than they are for native-born Swedes. As Figure 6 indicates, for most immigrant groups, the effective retirement age declined more steeply than it did for native-born Swedes prior to the mid-1990s, but it increased more sharply thereafter. This pattern may be attributable to foreign-born individuals having been more reliant than natives on disability pension benefits in the past, which in turn led to a more pronounced increase in their retirement age after the eligibility rules for disability pensions become stricter.

It is, moreover, likely that immigrants were more affected than natives by the oldage pension reform. The current old-age pension system calculates pension benefits based on an individual's earning history over his/her entire working life (whereas the previous system defined benefits based on the best 15 years of the worker's earning history). While natives usually spend their entire economic life-cycle in Sweden, migrants often do not. Thus, on average, the pension benefits migrants receive in the current pension system tend to be lower than those of natives, largely because they spend fewer years contributing to the system. One potential solution to this problem is for migrants to postpone retirement in order to increase the number of years they contributed to the system. If this is the strategy immigrants who have short working histories in Sweden tend to use, the impact of the pension reform may explain why the effective retirement age has increased more among immigrants than it has among natives. In addition to this institutional explanation, human capital reinvestment in mid- and late-life might be another factor that has contributed to the increase in the effective retirement age among low-skilled workers. In the 1997-2002 period, adult continuing education was radically expanded as part of the "Knowledge Lift" initiative, which had the goal of enhancing the human capital of workers with low to medium skill levels. More than $10 \%$ of the Swedish labour force participated in various adult training programs during this period (Bergemann and Van den 
Berg 2014). Since immigrants, particularly those from low-income countries, tend to have low skill levels, they might have benefited more than natives from this adult education expansion.

While some scholars have argued that workers with low initial levels of education benefit little from adult educational training (Heckman et al. 1999), there is evidence that the effect of this initiative on employment and wage levels among low-skilled mothers was positive (Bergemann and Van den Berg 2014). These findings imply that the impact of the "Knowledge Lift" in the 1990s might help to explain why the effective retirement age increased for less-educated and low-skilled workers. Moreover, if immigrants were indeed overrepresented in adult training programs, the impact of the initiative might also explain why the effective retirement age increased more among immigrants than among natives.

In addition, some scholars have argued that the increase in human capital investment for mid- and late-life workers might have been a side effect of the pension reform. Specifically, it has been suggested that the increased financial incentives for postponing retirement, coupled with the expectation of living longer, has prolonged the payback period for human capital reinvestment, and has therefore encouraged middle-aged workers to participate in training (Brunello and Comi 2015; Montizaan et al. 2010; Fouarge and Schils 2009). This argument essentially implies that pension reforms have played an important role in increasing the effective retirement age, albeit through an indirect mechanism mediated by human capital reinvestment. Such a mechanism might be particularly relevant for immigrants, at least up until age 65 , because, as a result of their shorter working histories, immigrants tend to have lower pension benefits than natives.

\section{Summary and discussion}

In Sweden, as in many other developed countries, the average age at retirement has increased for both men and women since the 1990s. Although these increases are helping to mitigate the consequences of population ageing, their magnitude has so far been too small to offset the general ageing trend. Thus, the average number of years spent in retirement is still increasing. This pattern, combined with the shrinking of the workforce, suggest that it will be difficult to sustain current levels social welfare transfers from the economically active population to the dependent elderly. To meet this challenge, working life needs to be further prolonged.

The current contribution-based old-age pension system in Sweden, which is only 20 years old, is already being modified. In February 2019, a proposal for a new pension reform was approved by legislators in the Swedish parliament. This reform mandates three major changes. First, the minimum age for receiving public oldage pension benefits will be gradually increased from 61 years in 2019 to 64 years in 2026. Second, the right to retain employment will be increased from age 67 currently to age 69 in 2023. Third, the age of eligibility for receiving guaranteed pension benefits (for those individuals who have little or no pension-qualifying 
income) will be gradually increased from 65 years in 2019 to 67 years in 2026 . The purpose of these new policies is to further increase the average effective retirement age. However, the critical question that has arisen is whether certain disadvantaged groups - such as those who have low levels of human capital or poor health, or who are immigrants from low-income countries - will be able to adapt to the new policy environment, and work longer.

In this paper, we have demonstrated that the increasing trend in the average effective retirement age since the mid-1990s has occurred across all socio-economic and demographic groups. The individuals who postponed retirement were not just the highly-educated/skilled, the healthy, and the native-born; they were also workers with less human capital, impaired health, and immigrant backgrounds. Indeed, men with the lowest educational levels had the steepest increases in the effective retirement age. This finding implies that the extension of working life is feasible for all groups, regardless of their socio-economic and demographic characteristics.

In terms of the incentives for late retirement, we believe that they are likely to vary across groups. For highly-educated and healthy workers, delaying retirement might simply be a response to the old-age pension reform. For low-skilled and unhealthy workers, working longer might also be a response to stricter eligibility rules for disability pensions. For immigrants, a combination of having relatively short work histories and low lifetime earnings might be an additional contributing factor. Moreover, human capital reinvestment, such as adult training programs, might play a role in extending the working lives of immigrants who have low skill levels and are from low-income countries.

Although this paper focuses on the Swedish experience in extending working life, it might be of interest for other ageing societies where concerns have been raised about whether workers engaged in physically demanding occupations will be able to work longer. Our figures suggest that increasing the statutory retirement age and/or removing early retirement incentives is possible even for the least educated, for those who have been hospitalised before the age of 60, and for immigrants born in low-income countries. The next question that arises is which policies and conditions are needed to enable people to work longer. Providing a concrete answer to this question would require us to have a thorough understanding of the factors that have driven the increase in the effective retirement age. More importantly, whether and, if so, how these underlying mechanisms might differ across population groups are questions to be addressed in future research.

\section{Acknowledgements}

We are grateful for financial support from the European Union's Seventh Framework Programme for research, technological development and demonstration under Grant Agreement No. 613247 (AGENTA), the Swedish Research Council (Vetenskapsrådet) via the Linnaeus Center for Social Policy and Family Dynamics in Europe (SPaDE) at Stockholm University, Grant Registration No. 349-2007-8701 and the 
Centre for Economic Demography (CED) at Lund University, Grant Registration No. 2006-00079, and the Swedish Research Council for Health, Working life and Welfare (FORTE), Grant Registration No. 2016-07115.

\section{References}

Altbach, P. G., L. Reisberg and L. E. Rumbley 2009. Trends in global higher education: Tracking an academic revolution. Paris: United Nations Educational, Scientific and Cultural Organization.

Atalay, K. and G. F. Barrett 2015. The impact of age pension eligibility age on retirement and program dependence: Evidence from an Australian experiment. The Review of Economics and Statistics 97: 71-87. Retrieved from http://ideas.repec.org/a/tpr/qjecon/ v118y2003i1p157-205.html

Bengtsson, T. and H. Qi 2018. Sweden. In Ageing workforce, social cohesion and sustainable development. Political challenges within the Baltic Sea region, eds P. Becker, J. Schütz and A. Zimmermann, 55-59. Berlin: Population Europe.

Bengtsson, T. and K. Scott 2010. The ageing population. In Population ageing - A threat to the welfare state? The case of Sweden, ed. T. Bengtsson, 7-22. Berlin: Springer.

Bengtsson, T. and K. Scott 2011. Population ageing and the future of the Swedish welfare state. Population and Development Review 37: Supplement.

Bergemann, A. and G. J. Van den Berg 2014. From giving birth to paid labor: The effects of adult education for prime-aged mothers. Working Paper 2014: 5. Uppsala: Institute for Evaluation of Labour Market and Education Policy.

Blau, D. M. and R. M. Goodstein 2010. Can social security explain trends in labor force participation of older men in the united states? The Journal of Human Resources 45: 328-363. Retrieved from http://www.jstor.org/stable/25703459

Brunello, G. and S. Comi 2015. The side effect of pension reforms on the training of older workers: Evidence from Italy. The Journal of the Economics of Ageing 6: 113-122. DOI: 10.1016/j.jeoa.2015.02.001

Chudnovskaya, M. and M. Kolk 2015. Educational expansion and intergenerational proximity in Sweden. Population, Space and Place 23: 1973. DOI: 10.1002/psp.1973

Coale, A. J. 1957. How the age distribution of a human population is determined. Cold Spring Harbor Symposia on Quantitative Biology 22: 83-89.

Fouarge, D. and T. Schils 2009. The effect of early retirement incentives on the training participation of older workers. LABOUR 23: 85-109. DOI: 10.1111/j.1467-9914.2008. 00441.x

Gustafsson, B. A., H. Mac Innes and T. Österberg 2018. Fattigdom bland äldre handlar allt mer om utrikes födda. Ekonomisk Debatt.

Hagen, J. 2013. A history of the Swedish pension system. Working Paper Series, Center for Fiscal Studies, Uppsala University, Department of Economics. Retrieved from http://ideas.repec.org/p/hhs/uufswp/2013_007.html

Heckman, J. J., R. J. LaLonde and J. A. Smith 1999. The economics and econometrics of active labor market programs. In Handbook of labor economics, eds O. Ashenfelter and D. Card, Vol. 3. North-Holland. 
Heisig, J. P., B. Lancee and J. Radl 2017. Ethnic inequality in retirement income: A comparative analysis of immigrant-native gaps in western Europe. Ageing and Society 38: 1963-1994. DOI: 10.1017/s0144686x17000332.

Johansson, P., L. Laun and M. Palme 2015. Pathways to retirement and the role of financial incentives in Sweden. In Social security programs and retirement around the world, ed. D. Wise, 369-410. Chicago: University of Chicago Press. DOI: $10.7208 /$ chicago/9780226262604.003.0009

Karampampa, K., T. Andersson, S. Drefahl, A. Ahlbom and K. Modig 2014. Does improved survival lead to a more fragile population: Time trends in second and third hospital admissions among men and women above the age of 60 in Sweden. PLOS ONE 9: 1-6. DOI: 10.1371/journal.pone.0099034

Karampampa, K., S. Drefahl, T. Andersson, A. Ahlbom and K. Modig 2013. Trends in age at first hospital admission in relation to trends in life expectancy in Swedish men and women above the age of 60. BMJ Open 3: DOI: 10.1136/bmjopen-2013-003447

Karlström, A., M. Palme and S. Ingemar 2008. The employment effect of stricter rules for eligibility for DI: Evidence from a natural experiment in Sweden. Journal of Public Economics 92: 2071-2082.

Laun, L. and M. Palme 2017. The recent rise of labor force participation of older workers in Sweden. Working Paper 2017: 17. Uppsala: Institute for Evaluation of Labour Market and Education Policy.

Laun, T. and J. Wallenius 2015. A life cycle model of health and retirement: The case of Swedish pension reform. Journal of Public Economics 127: 127-136.

Lee, R. D. 1994. The formal demography of population ageing, transfer, and the economic life cycle. In Demography of ageing, eds L. G. Martin and S. H. Preston, 8-49. Washington, DC: National Academy Press.

Lee, R. D. and Y. Zhou 2017. Does fertility or mortality drive contemporary population aging? the revisionist view revisited. Population and Development Review 43: $285-301$.

Maestas, N. and J. Zissimopoulos 2010. How longer work lives ease the crunch of population aging. Journal of Economic Perspectives 24: 139-60. DOI: 10.1257/jep.24.1.139

Modig, K., T. Andersson, S. Drefahl and A. Ahlbom 2013. Age-specific trends in morbidity, mortality and case-fatality from cardiovascular disease, myocardial infarction and stroke in advanced age: Evaluation in the Swedish population. PLOS ONE 8: 1-13. DOI: 10.1371/journal.pone.0064928

Modig, K., S. Drefahl, T. Andersson and A. Ahlbom 2012. The aging population in Sweden: Can declining incidence rates in MI, stroke and cancer counterbalance the future demographic challenges? European Journal of Epidemiology 27: 139-145. DOI: $10.1007 / \mathrm{s} 10654-012-9653-2$

Montizaan, R., F. Corvers and A. D. Grip 2010. The effects of pension rights and retirement age on training participation: Evidence from a natural experiment. Labour Economics 17: 240-247. DOI: 10.1016/j.labeco.2009.10.004

Murphy, M. 2017. Demographic determinants of population aging in Europe since 1850. Population and Development Review 43: 257-283. 
OECD 2017. Pensions at a Glance 2017: OECD and G20 Indicators. Paris: OECD Publishing. DOI: $10.1787 /$ pension_glance-2017-en

OECD 2019, Employment rate by age group (indicator). DOI: 10.1787/084f32c7-en

Pensionsmyndigheten 2018. Arsredovisning 2017. Tech. rep., Pensionsmyndigheten (The Swedish Pension Agency), Stockholm.

Qi, H. 2016. Live longer, work longer? evidence from Sweden's ageing population. Lund University. Department of Economic History, Lund University.

Qi, H., T. Bengtsson and J. Helgertz 2016. Old-age employment in Sweden: The reversing cohort trend. In: Live longer, work longer? evidence from Sweden's ageing population, ed. H. Qi, 117-164. Lund: Department of Economic History, Lund University.

Qi, H., J. Helgertz and T. Bengtsson 2018. Do notional defined contribution schemes prolong working life? evidence from the 1994 Swedish pension reform. The Journal of the Economics of Ageing. DOI: 10.1016/j.jeoa.2016.11.001

SCB 2017. Swedish and foreign-born population by region, age and sex. Year 2000-2017. Retrieved from http://www.statistikdatabasen.scb.se

SCB 2018. Statistical database. Retrieved from http://www.statistikdatabasen.scb.se

Scherer, P. 2002. OECD labour market and social policy occasional papers. Organisation for Economic Co-Operation and Development (OECD). DOI: 10.1787/18151981

Schirle, T. 2008. Why have the labor force participation rates of older men increased since the mid-1990s? Journal of Labor Economics 26: 549-594. Retrieved from http://www.jstor.org/stable/10.1086/589457

Sjogren Lindquist, G. 2017. Utrikes föddas pensioner idag och i framtiden (Pensions for foreign born today and in the future). Unpublished.

Staubli, S. and J. Zweimuller 2013. Does raising the early retirement age increase employment of older workers? Journal of Public Economics 108: 17-32. DOI: 10.1016/j.jpubeco.2013.09.003

UN 2015. World population ageing 2015. Department of Economic and Social Affairs, Population Division (ST/ESA/SER.A/390). 